\title{
Genetic ancestry and health
}

\begin{abstract}
Information about genetic ancestry has a great value in health studies and other related areas of expertise such as anthropology, forensics and pharmacogenomics. In this review, we highlight several aspects of health that can be significantly improved by better understanding of genetic ancestry. These observations were made possible based on our own medical genetic research in Asia/Pacific populations (i.e. in particular regarding Maori and Orang Asli of New Zealand and Peninsular Malaysia, respectively). The major objectives of this programme of investigations has been to capture and understand genetic diversity in these populations and subsequently to make recommendations in order to maximise the health benefits of this type of population genetic research.
\end{abstract}

Keywords: genetics, ancestry, health, Polynesians, maori, Malays, orang asli, new Zealand, Malaysia
Volume 5 Issue 2 - 2017

\section{Hisham Atan Edinur,' Geoffrey Keith Chambers $^{2}$ \\ 'School of Health Sciences, Universiti Sains Malaysia, Malaysia ${ }^{2}$ School of Biological Sciences, Victoria University of Wellington, New Zealand}

Correspondence: Hisham Atan Edinur, Forensic Science Programme, School of Health Sciences, Universiti Sains Malaysia, Health Campus, 16150, Kubang Kerian, Kelantan, Malaysia, , Tel 609-767764I, Fax 609-7677515, Email edinur@usm.my

Received: January 31, 2017| Published: February 16, 2017
Abbreviations: HPA, human platelet antigen; HNA, human neutrophil antigen; MICA, major histocompatibility complex class i chain-related gene A; HLA, human leukocyte antigen; KIR, killer cell immunoglobulin-like receptor; SNP, single nucleotide polymorphism

\section{Introduction}

Genetic methods play a significant role in many research areas including medicine, forensics and ancestry study. In this respect, we highlight the ways in which knowledge about genetic ancestry has become an important element in health and medical treatments. This viewpoint is largely based on our own experience working on various genetic markers in Asia/Pacific populations such as Maori, Polynesians, Malays and Orang Asli in New Zealand, Pacific Islands and Malaysia. These diagnostic markers include many loci (e.g. HLA, blood group, HPA, cytokines and HNA) that determine transfusion and transplant success, our immune responses to disease and as causal agents in autoimmunity.

\section{Ancestry and health}

We have completed and reported a comprehensive set of ancestrally informative genetic data across many Asia/Pacific populations. These systems include HLA, MICA, KIR, blood group, cytokine, HNA and HPA. ${ }^{1-20}$ These new datasets not only provide special insights into the ancestry of these people, but also is of significant value in health; as recently reviewed by. ${ }^{21-22}$ This is because these genes are determinants of transfusion and transplant success or have been directly associated with other immune and important biological functions. For example, matching of HLA markers between patient and donor is important before proceeding with transplant operations. Certain HLA types have also been shown to be contributing factors in the pathogenesis of various diseases. ${ }^{23}$ In the following sub-sections, we will discuss several aspects of health which can be significantly improved based on our understanding of ancestry and genetic diversity in Maori, Malays, Orang Asli and several Polynesian sub-populations.

Allelic variations and disease prevalence: Many diseases have been mapped to particular regions of the human genome and certain allelic types have been associated with high risk of disease susceptibility. In this context, relative risk of autoimmune diseases can be predicted from the prevalence of particular antigen types in a population. For example, medical conditions such as ankylosing spondylitis and rheumatoid arthritis are rare in Maori/Polynesians, but relatively common among Europeans. They are typically associated with the $H L A-B * 27: 05$ and $H L A-D R B 1 * 04: 01$ tissue types in Europeans and $H L A-B * 27: 04$ and $H L A-D R B 1 * 04: 05$ in Asians/Polynesians, respectively. ${ }^{24-26}$ The $H L A-B * 27: 04$ and $H L A-D R B 1 * 04: 05$ alleles are quite rare in Polynesians (0-0.01 and 0.02-0.08, respectively) which may explain the unusually low occurrence of ankylosing spondylitis and rheumatoid arthritis in Maori/Polynesians. ${ }^{5}$

Candidate genes for disease study: Many genetic markers characterized in various populations across the globe are now available as population datasets and can be readily retrievable from public databases; e.g. see $^{8}$ for Allele Frequencies.net and ${ }^{27}$ for IPD Immuno Polymorphism Database. These datasets can be used not only as a reference standard for disease association studies (see later), but also provide important resources to search for candidate susceptibility genes in disease studies. A good candidate gene(s) will be one with greatest differences in allele frequency among populations, including between ethnically related populations which show different schedules of disease prevalence. This is one of the main molecular signatures of the highly polymorphic immune system genes, where patterns of allelic variation at population level are shaped by local demographic or selective factors; e.g. see. ${ }^{17,28}$

Donor recruitment: In general, compatible donor for a particular patient might best be recruited from his/her own group or other ethnically related groups because they tend to share a common (if not identical) alleles. But this will not always be the case because founder effects, admixture and assimilation over a period of time might change the ancestral fractions in descendant populations. However, this is not the situation for patient with a rare genotype. Instead, their particular genotypic combination in might be more common in another unrelated population; e.g. HNA-5a/5a was reported to be fixed in Orang Kanaq, a Proto-Malay population in Peninsular Malaysia. However, other HNA-5 genotypes (HNA-5a/5b and HNA-5b/5b) are likely also to be present in Orang Kanaq patients, albeit at very low frequency, and their compatible donor would then be most easily found by searching among members of other Orang Asli groups or Malays. ${ }^{9-10}$

The number or size of recruited donor pools should depend on the distributions of allelic spectra at the population level (i.e. particularly those coding for transplant or transfusion determinants such as HLA or the ABO and Rhesus blood groups, respectively). Thus a small and highly homogeneous population might only need to have a small number of recruited donors, while a larger multi-ethnic country with 
people having diverse genetic backgrounds (like Malaysia or New Zealand) should have much larger numbers of recruited donors in order to increase the proportions of those with rare phenotype profiles. Special consideration should be given to inter-group marriage which will introduce donors/patients with admixed genetic repertoires. The admixed ethnicity group will have a reduced number of potential donors available from un-admixed groups. However, with the passage of time they will be expected to gradually become the genetically dominant donor group in the population.

Tissue typing strategies: Our various surveys have tested many different molecular techniques for genotyping particular genetic loci; see..$^{5,20}$ Our experimental design proved to have value in medical genetic applications. The human genome has now been fully sequenced and very many new molecular typing techniques have been developed, tested and validated for regions of particular interest on chromosomes. Unlike next generation sequencing technology which is fully capable of capturing data from entire coding/non-coding regions, earlier techniques such as sequence based typing (SBT) and sequence specific primer (SSP) recorded only relatively small specifically targeted segments of the human genome. Both, SBT and SSP can reflect serological expression provided that all genetic variants associated with a particular phenotype can be included in the screen. For example, Duffy blood group phenotypes might be falsely identified if clinical analysts only identify the $125 \mathrm{G}>\mathrm{A}$ SNP ( $F Y^{*} A$ to $F Y^{*} B$ alleles, respectively) on chromosome $1 .{ }^{29}$ Two further SNPs $(67 \mathrm{~T}>\mathrm{C}$ and $286 \mathrm{C}>\mathrm{T})$ in the sequence encoding the $\mathrm{FY} * B$ allele should also be scored for erythroid silent Fy(a-b-) and weak (Fyabweak) expression of Duffy antigens, respectively. ${ }^{30-32}$ The erythroid silent variant is common in Africa, but relatively rare in the other populations. ${ }^{1,6,33}$ Hence, high resolution molecular screening of the erythroid silent variant in donors and patients could significantly reduce false prediction rates for Duffy phenotypes in African populations.

Wider applications of population data for ethnically related populations: From a genetic standpoint, any research conducted on individual groups of people might have beneficial values for others, especially for closely related populations. For example, cytokines and HNA have never been genetically characterized in Maori and Polynesians. However, markers frequencies have been reported for both types of loci in some of their Austronesian relatives; namely the Malay subethnic groups. ${ }^{9-13}$ In this context, these datasets from Malay subethnic groups can be used as a prospective guide to values for Maori and Polynesians. Nonetheless, any such inferences should be made with caution because each population might have experienced different evolutionary pressures after they split from one another around 5000years ago. A most obvious example is that provided by our recent work on cytokine gene SNPs in Malays and Orang Asli where significant differences were recorded not only between Orang Asli groups (Semang vs. Senoi. vs. Proto-Malays), but also between their sub-groups; Lanoh vs. Kensiu vs. Bateq of Semang group. ${ }^{12-13}$

\section{Conclusion}

Overall, our understanding of genetic ancestry has a great potential to inform health and other related areas such as in forensic DNA studies and pharmacogenomics..$^{22,34-37}$ The major challenges ahead are to investigate, describe and understand genetic variability in order to maximise the health benefits of population genetic research.

\section{Acknowledgements}

None.

\section{Conflicts of interest}

Author declares there are no conflicts of interest.

\section{Funding}

None.

\section{References}

1. Abd Gani R, Manaf SM, Zafarina Z, et al. Molecular blood group typing in Banjar, Jawa, Mandailing and Kelantan Malays in Peninsular Malaysia. Transfus Apher Sci. 2015;53(1):69-73.

2. Askar M, Daghstani J, Thomas D, et al. 16th IHIW: Global distribution of extended HLA haplotypes. Int J Immunogenet. 2013;40(1):31-38.

3. Edinur HA, Zafarina Z, Spínola H, et al. HLA polymorphism in six Malay sub-ethnic groups in Malaysia. Hum Immunol . 2009;70(7):518-526.

4. Edinur HA, Dunn PP, Hammond L, et al. Using HLA loci to inform ancestry and health in Polynesian and Maori populations. Tissue Antigens . 2012;80(6):509-522.

5. Edinur HA, Dunn PP, Hammond L, et al. HLA and MICA polymorphism in Polynesians and New Zealand Maori: implications for ancestry and health. Hum Immunol . 2013a;74(9):1119-1129.

6. Edinur HA, Dunn PPJ, Lea RA, et al. Molecular approaches to transfusion medicine in Polynesians and Maori in New Zealand. Int $J$ Immunogenet. 2013;40(6):460-470.

7. Edinur HA, Dunn PP, Lea RA, et al. Human platelet antigens frequencies in Maori and Polynesian populations. Transfus Med. 2013;23(5):330-337.

8. González-Galarza FF, Takeshita LY, Santos EJ, et al. Allele frequency net 2015 update: new features for HLA epitopes, KIR and disease and HLA adverse drug reaction associations. Nucleic Acids Res. 2015;43(Database issue):D784-D788.

9. Manaf SM, Nur Waliyuddin HZA, Panneerchelvam S, et al. Human Neutrophil Antigen Profiles in Banjar, Bugis, Champa, Jawa and Kelantan Malays in Peninsular Malaysia. Blood Transfus. 2015a;13(4):1-6.

10. Manaf SM, Wan Syafawati WU, Panneerchelvam S, et al. HNA Diversity in Six Subgroups of Orang Asli in Peninsular Malaysia. Transfus Med . 2016;26(4):305-307.

11. Nemat-Gorgani N, Edinur HA, Hollenbach JA, et al. KIR diversity in Māori and Polynesians: populations in which HLA-B is not a significant KIR ligand. Immunogenetics . 2014;66(11):597-611.

12. Norhalifah HK, Zafarina Z, Sundararajulu P, et al. Distribution of cytokine gene polymorphisms in five Malay subethnic groups in Peninsular Malaysia. Int J Immunogenet . 2015;42(3):200-203.

13. Norhalifah HK, Zafarina Z, Sundararajulu P, et al. Distribution of cytokine gene polymorphisms in six Orang Asli subgroups in Peninsular Malaysia. Hum Immunol . 2016;77 (4):338-339.

14. Nur Haslindawaty AR, Panneerchelvam S, Edinur HA, et al. Sequence polymorphisms of mtDNA HV1, HV2, and HV3 regions in the Malay population of Peninsular Malaysia. Int $J$ Legal Med . 2010;124(5):415-426.

15. NurWaliyuddin HZA, Edinur HA, Norazmi MN, et al. Killer immunoglobulin-like receptor diversity in Malay sub-ethnic groups of Peninsular Malaysia. Int J Immunogenet . 2014;41(6):472-479.

16. NurWaliyuddin HZA, Edinur HA, Norazmi MN, et al. Ancient genetic signatures of Orang Asli revealed by killer immunoglobulin-like receptor gene polymorphisms. PLoS ONE. 2015;10(11):141-536.

17. Riccio ME, Buhler S, Nunes JM, et al. 16th IHIW: Analysis of HLA Population Data, with updated results for 1996 to 2012 workshop data (AHPD project report). Int J Immunogenet . 2013;40(1):21-30. 
18. Tasnim AR, Allia S, Edinur HA, et al. Distribution of HLA-A, -B and -DRB1 alleles in the Kensiu and Semai Orang Asli sub-groups in Peninsular Malaysia. Hum Immunol. 2016;77(8):618-619.

19. Wan Syafawati WU, Norhalifah HK, Syaza FH, et al. Allele frequencies of human platelet antigens in Banjar, Bugis, Champa, Jawa and Kelantan Malays in Peninsular Malaysia. Transfus Med . 2015;25(5):326-332.

20. Wan Syafawati WU, Norhalifah HK, Syaza FH, et al. Human platelet antigen allelic diversity in Peninsular Malaysia. Immunohematology. 2016 .

21. Chambers GK, Edinur HA. The Austronesian Diaspora: A Synthetic Total Evidence Model. Global Journal of Anthropology Research. 2015;2(2):53-65.

22. Chambers GK, Edinur HA, Dunn PPJ. New insights into ancestry and health of Polynesians and New Zealand Maori. New Zealand Science Review. 2016;73(1):3-10

23. Blackwell JM, Jamieson SE, Burgner D. HLA and infectious diseases. Clin Microbiol Rev. 2009;22(2):370-385.

24. Brown MA, Pile KD, Kennedy LG, et al. HLA class I associations of ankylosing spondylitis in the white population in the United Kingdom. Ann Rheum Dis.. 1996;55(4):268-270.

25. Lopez-Larrea C, Sujirachato K, Mehra NK, et al. HLA-B27 subtypes in Asian patients with ankylosing spondylitis. Evidence for new associations. Tissue Antigens. 1995;45(3):169-176.

26. Tan OL, Farmiloe S, Roberts M, et al. HLA-DR4 subtypes in New Zealand Polynesians. Predominance of Dw13 in the healthy population and association of Dw15 with rheumatoid arthritis. Arthritis Rheum. 1993;36(1):15-19.

27. Robinson J, Halliwell J, Hayhurst J, et al. The IPD and IMGT/HLA database: allele variant databases. Nucleic Acids Res. 2015; 43(Database issue):D423-D431.
28. Hollenbach JA, Augusto DG, Alaez CL, et al. 16th IHIW: population global distribution of killer immunoglobulin-like receptor (KIR) and ligands. Int J Immunogenet. 2013;40(1):39-45.

29. Reid ME, Lomas-Francis C. The blood group antigen factsbook. Academic Press, San Diego, California, USA. 2004.

30. Rios M, Chaudhuri A, Mallinson G, et al. New genotype in Fy (a-b-) individual: nonsense mutations (Trp to stop) in the coding sequence of either FY A or FY B. Br J Haematol. 2000; 108(2):448-454.

31. Tournamille C, Colin Y, Cartron JP, et al. Distruption of a GATA motif in the Duffy gene promoter abolishes erythroid gene expression in Duffynegative individual. Nat Genet. 1995;10(2):224-228.

32. Tournamille C, Le Van Kim C, Gane P, et al. Arg89Cys substitution results in very low membrane expression of the Duffy antigen/receptor for chemokines in Fyx individuals. Blood . 1998;92(6):2147-2156.

33. Meny GM. The Duffy blood group system: a review. Immunohematology. 2010;26(2):51-56

34. Lea RA, Benowitz $N$, Green $M$, et al. Ethnic differences in nicotine metabolic rate among New Zealanders. $N Z$ Med $J$. 2005;118(1227):U1773

35. Lea RA, Chambers GK. Monoamine oxidase, addiction, and the warrior gene hypothesis. NZ Med J. 2007;120(1250):U2441.

36. Lea RA, Roberts RL, Green MR, et al. Allele frequency differences of cytochrome P450 polymorphisms in a sample of New Zealand Maori. NZ Med J. 2008;121(1272):33-37.

37. Lea RA, Chambers GK. Pharmacogenetics in admixed populations in Polynesia. In: Suarez-Kurtz G (Ed.) Pharmacogenomics. Landes Bioscience, Austin, Texas, USA. 2007. p.164-189. 